\title{
Vocal range profile in elderly women with and without voice symptom
}

\author{
Mariana Rebeka Gomes Queiroz ${ }^{1}$ \\ https://orcid.org/0000-0003-2109-1960 \\ Adriana de Oliveira Camargo Gomes ${ }^{1}$ \\ https://orcid.org/0000-0002-1871-9502
}

Jonia Alves Lucena ${ }^{1}$

https://orcid.org/0000-0001-5924-3451

Universidade Federal de Pernambuco UFPE, Departamento de Fonoaudiologia, Recife, Pernambuco, Brasil.

Conflict of interests: Nonexistent

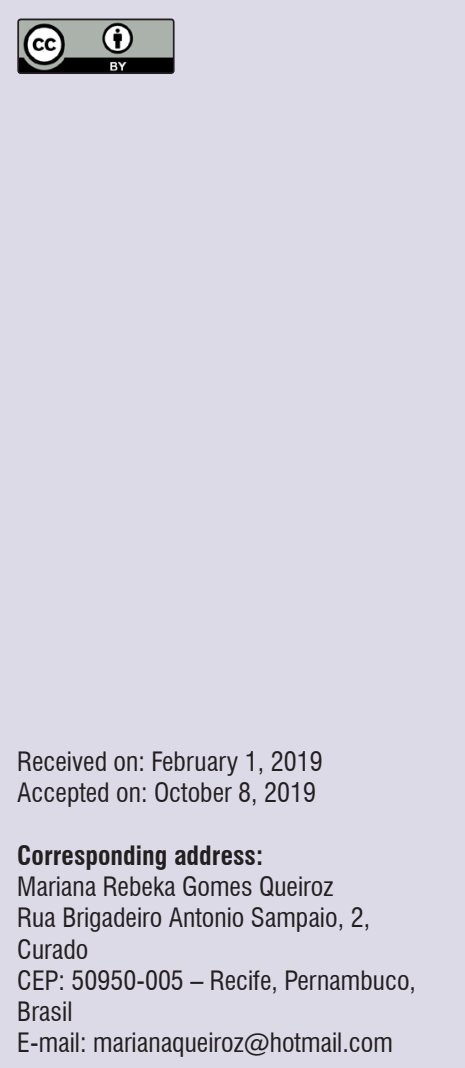

\section{ABSTRACT}

Purpose: to characterize and compare the vocal range profile in elderly women with and without voice symptoms.

Methods: a total of 23 elderly women attending an elderly care public service participated in the study. They were divided into groups - with and without voice symptoms, according to the results of the Voice Symptom Scale (VoiSS). All participants were submitted to a vocal range profile analysis, by means of the Vocalgrama software. Appropriate statistical tests were applied, by adopting a significance level lower than 0.05 .

Results: the values for vocal range profile were $3.74 \%( \pm 1.56)$ and $3.62 \%( \pm 1.95)$ in the groups with and without symptoms, respectively. There were no differences between the groups in the various parameters of the vocal range profile.

Conclusion: in the elderly women studied, the vocal range profile showed to be reduced, regardless of having or not voice symptoms. The importance of the elderly investing in the possibilities of vocal training is highlighted, with emphasis on vocal flexibility, aiming at increasing vocal range in this population.

Keywords: Voice; Singing; Aging; Voice Quality 


\section{INTRODUCTION}

Each cycle of life has its own particularities, and the phase of senescence is not an exception. In this stage, decline in the daily activities are perceived, interfering with their quality of life, as well as diminishing their cognitive, sensorial and motor aspects ${ }^{1,2}$. Among these changes, it is common to find, in speech-languagehearing clinics, voice problems resulting from the aging process, called presbyphonia.

Some characteristics related to voice aging, as inherent to the patient's age, stand out: decrease in respiratory capacity, decrease in maximum phonation time, hoarse-breathy vocal quality, decrease in vocal intensity ${ }^{3-5}$, and changes in voice frequency-10. Men's fundamental frequency is set around $147 \mathrm{~Hz}$, which represents a high value for males; among females, this acoustic parameter often averages $195 \mathrm{~Hz}$, which represents a low value for women.

The presence of reduced vocal intensity is related to the deficient respiratory support, due to the diminished elasticity and the stiffening of the respiratory musculature, as well as the decrease in vital capacity and maximum phonation time. Such set of factors favors a decreasing infraglottic pressure and, consequently, a reduction in voice intensity 4.5 .

Another relevant symptom in this population is the difficulty to sing. Many times, elderly refer to difficulties in reaching extreme notes ${ }^{4}$, which may be related to changes in vocal range. Some authors highlight the restricted tonal range as one of the acoustic changes present in this population ${ }^{11}$. This characteristic may particularly have a negative influence in singing.

It is important to mention that the elderly are more and more integrated in community activities, such as singing groups or choirs, which favors a better quality of life in physical, psychological and social aspects, improving their well-being ${ }^{12,13}$. However, it is noticed that the vocal characteristics oftentimes presented by the senescent interfere with their singing performance, causing complaints to arise concerning their difficulty to sing ${ }^{4}$.

Furthermore, the presence of negative vocal symptoms, as coughing, throat clearing, screaming, difficulty to speak, and vocal fatigue interfered with the vocal range performance of elderly women chorists, especially in the group presenting greater occurrence of these vocal symptoms ${ }^{14}$.

Hence, the elderly may feel disadvantaged before a vocal problem or limitation, no longer being able to join group activities that specifically use the voice, thus shying away and even isolating themselves.

For the assessment of intensity-related vocal range, i.e., analysis of phonatory and dynamic ranges, there are acoustic-measuring devices, such as phonetography and the Vocalgrama, for example, which enables the measurement of the maximum and minimum frequency and intensity limits a person can reach, producing a graph whose area is measured in square centimeters or in percentage. Therefore, the greater the represented area, the better is the vocal performance, in relation to frequency and intensity control ${ }^{15}$.

In this article, the purpose was to measure the vocal range profile in elderly women, with and without vocal symptoms, considering the vocal and dynamic ranges, aiming at verifying the impact of age and vocal symptoms on these parameters. Such purpose is justified by the fact that the results obtained may furnish means to propose vocal training alternatives for this population, as well as to control the effects of the training applied. The goal is to renew the possibilities of activities for the elderly in the social context, as in singing, for example, making improvements in their quality of life possible.

Thus, the initial hypothesis for this research was that elderly women without vocal symptoms may have better results in vocal range profile measurements, when compared to those with symptoms. In addition, it was assumed that elderly women have reduced vocal range in relation to the adult women population. Hence, this paper aimed at characterizing and comparing the vocal range profile in elderly women with and without voice symptoms.

\section{METHODS}

This is an analytical, comparative, cross-sectional research, characterized as a subproject of a broad study already submitted to and approved by the Research Ethics Committee of the Universidade Federal de Pernambuco, Brazil, under Certificate of Presentation for Ethical Consideration (CAAE)447252215.6.0000.5208, evaluation report no. 1.076 .660 . The sample was collected from an elderly care public service, counting on the participation of 23 elderly women aged from 62 to 76 years, averaging $69.42( \pm 4.88)$ years old.

The individuals included in the research were women 60 years old or over, attending an elderly care public service from a public university. Elderly women with illnesses that could affect the proper functioning of the vocal tract, such as stroke, Parkinson's disease, 
dementia, and respiratory tract chronic diseases were excluded from the sample, as well as those that had been submitted to head and neck surgery. For such, the patients' medical history was consulted in the healthcare unit.

Initially, the elderly women were informed about the study, and those who agreed to participate signed the Informed Consent Form (ICF). Then, the Voice Symptom Scale (VoiSS) protocol was applied, in order to divide them in two groups: with and without vocal symptoms, according to the score achieved on the protocol; the passing score was set at 16 points $^{16}$, as shown in Table 1. The group without symptoms was composed of 12 elderly women, aged from 62 to 73 (average: $69.57 \pm 5.69$ years). The group with vocal symptoms was composed of 11 elderly women, aged from 63 to 76 (average: $69.28 \pm 4.33$ ). It is noted that the groups differed from each other in all domains of the scale.

Table 1. Distribution of the total, limitation, emotional and physical domains of the Voice Symptoms Scale, according to the groups with and without vocal symptoms

\begin{tabular}{cccccc}
\hline \multirow{2}{*}{ Domains } & \multicolumn{2}{c}{ With symptoms $(\mathbf{n}=\mathbf{1 1})$} & \multicolumn{2}{c}{ Without symptoms $(\mathbf{n}=\mathbf{1 2})$} & \multirow{2}{*}{ p-value* $^{*}$} \\
\cline { 2 - 5 } & Average & SD & Average & SD & 0.000 \\
Total & 30.82 & 13.94 & 7.92 & 4.66 & 0.000 \\
Limitation & 18.55 & 9.80 & 4.50 & 3.96 & 0.004 \\
Emotional & 4.91 & 5.90 & 0.17 & 0.57 & 0.003 \\
Physical & 7.36 & 2.61 & 3.25 & 2.76 & \\
\hline
\end{tabular}

* Mann-Whitney Test- level of significance $p<0.05$

$\mathrm{SD}=$ Standard Deviation

Afterwards, the data related to vocal and dynamic ranges of all participants were collected by means of the Vocalgrama software, which takes the measurements of the frequency and intensity acoustic parameters in their maximum and minimum limits, and of the voice range profile (VRP), in percentage.

The VRP enables the vocal limits of a person to be analyzed through the definition of the maximum and minimum frequency and intensity acoustic parameters. The VRP is set by means of the Vocalgrama software, made by "CTS Informática." This program quantifies, in exact figures, the person's range and translates it into a graph. Its analysis consists of the following measures: Hertz $(\mathrm{Hz})$ for the frequencies and pitch range; semitones for vocal range; decibels $(\mathrm{dB})$ for the maximum and minimum limits of voice intensity; and, percentage for the graph area corresponding to the vocal range profile $e^{15,17}$.

The data from the VRP were obtained through the vocal records identified in the program itself. The recordings were made with the use of an HP Notebook PC computer, connected to a Karsect HT-2 headset microphone and Andrea PureAudio ${ }^{\mathrm{TM}}$ USB-AS Adaptor, which filters and reduces noise. The microphone was kept at a distance of, approximately, four centimeters from the mouth, in order to minimize interferences in the records.

The vocal records of the VRP were made while the person was in the sitting position. Each participant was instructed to perform a sustained emission of the phoneme $/ \varepsilon /$ in upward and downward glissando, until they reached their maximum frequency limit, both for highs and lows, in the weakest intensity possible, and then in the strongest. The graph result registered by the program was described quantitatively, in percentage. All the records were obtained individually in a previously scheduled appointment between researcher and participant, in a room reserved for collecting the data.

For the data analysis, the acquired values were numerically distributed. The variables included the maximum and minimum frequencies, the maximum and minimum intensity, vocal range in number of semitones and in Hertz, and the area of the vocal range profile in percentage. Moreover, the presence or not of vocal symptoms was taken into consideration. To investigate the normality of the studied population, the Shapiro-Wilk test was performed. Considering that most of the variables studied presented non-normal 
distribution, it was then opted for the use of the Mann-Whitney non-parametric test for the comparison between averages. The SPSS software (Statistical Package for the Social Sciences), version 21.0, was used, and the significance level adopted was lower than $5 \%$.

\section{RESULTS}

Table 2 presents the average values of the vocal range profile variables in elderly women with and without vocal symptoms. It is observed that there was similarity between the values obtained from the groups, without significant differences being registered.

Table 2. Distribution of the variables of vocal range profile in elderly women, according to the groups with and without vocal symptoms

\begin{tabular}{cccccc}
\hline Variables of the & \multicolumn{2}{c}{ With symptoms } & \multicolumn{2}{c}{ Without symptoms } & \multirow{2}{*}{ p-value } \\
\cline { 2 - 5 } vocal range profile & Average & SD & Average & SD & 0.712 \\
Minf0 (Hz) & 153.89 & 34.19 & 158.25 & 32.31 & 0.758 \\
MaxfO (Hz) & 386.35 & 100.1 & 374.65 & 67.85 & 0.975 \\
PR (Hz) & 231.54 & 101.14 & 216.40 & 80.07 & 0.854 \\
PR (st) & 15.96 & 6.17 & 14.98 & 4.67 & 0.538 \\
Min Int (dB) & 54.18 & 6.75 & 55.64 & 5.67 & 0.854 \\
Max Int (dB) & 99.84 & 6.32 & 100.67 & 4.93 & 0.782 \\
Area (\%) & 3.74 & 1.56 & 3.62 & 1.95 & \\
\hline
\end{tabular}

* Mann-Whitney Test - level of significance $p<0.05$

Legend: Minfo: Minimum fundamental frequency; Max f0: Maximum fundamental frequency; PR: Pitch Range; Min Int: Minimum vocal intensity; Max Int: Maximum vocal intensity; Hz: Hertz; st: semitone; dB: decibel; SD: Standard Deviation; \%: percentage

\section{DISCUSSION}

This study aimed at characterizing and comparing the vocal range profile in elderly women, according to the presence or absence of vocal symptoms.

Regarding the minimum frequency measurements, the averages were found to be approximate between the groups, agreeing with what was observed in another research on vocal range profile in elderly women, using phonetography, whose average result was of 154 $\mathrm{Hz}^{18}$. Such values are inferior to those found in young women population, whose average was of $167.32 \mathrm{~Hz}$ in women aged from 18 to 29 years $^{19}$. It is possible that the farther reach towards lower frequencies occurred due to the lowering of frequency, commonly found in old age women. It so happens that, with menopause, the hormonal fall may trigger the vocal fold edema and, consequently, the lowering of the elderly women's voice $^{6,7}$. Moreover, it is interesting to notice that elderly chorist women may present an even lower reach, possibly resulting from training. A research has presented average values corresponding to $134.82 \mathrm{~Hz}$ and $137.28 \mathrm{~Hz}$ in elderly chorist women of two different age groups ${ }^{14}$.

Concerning maximum frequency, this study presented average value of $386.35 \mathrm{~Hz}$ for the group of elderly women with voice symptoms, and $374.65 \mathrm{~Hz}$ for the group of elderly women without voice symptoms. Another study, on the other hand, presented an average value of $478.88 \mathrm{~Hz}$, most of the elderly women presenting frequencies at about $440 \mathrm{~Hz}^{18}$. In young women, these values are much higher, and the reach towards high notes goes as far as $1000 \mathrm{~Hz}$, with average value of $908.45 \mathrm{~Hz}$ for the maximum frequencies of women between 18 and 29 years $^{20}$. The differences registered between young and elderly women are also expected, as the loss of vocal flexibility due to laryngeal changes in old age is taken into consideration ${ }^{21,22}$. In chorists, on the other hand, the registered average reach for younger elderly women was of $349.96 \mathrm{~Hz}$, whereas the group of older elderly women had an average value of $348.59 \mathrm{~Hz}^{14}$. Hence, it is reinforced the difficulty to reach higher frequencies in old age.

As for the pitch range in $\mathrm{Hz}$ and semitones, this study, in addition to not differing between the groups of elderly women with and without voice symptoms, presented results that diverged from those obtained from another group of elderly women, whose average was of $324.05 \mathrm{~Hz}^{18}$, possibly because the elderly women in this study had reached lower values of maximum frequency, as mentioned above. Such results are also below the values found in the adult population, whose established normality is of at least 20 semitones $^{19,20,23}$, 
with average records of 19.6 semitones in elderly women, and average of 28 semitones in young women. These findings may also be explained by the endocrinal factors related to the postmenopause period in women aged 60 or over. It should be further noted that chorist and non-chorist elderly may have their range in different semitones, and singing is a practice that may help to increase such measurement ${ }^{24}$.

As for the vocal range area, this study presented an average of $3.74 \%$ and $3.62 \%$, respectively, in elderly women with and without voice symptoms, which is considered as reduced in relation to the vocal range area of adult women ${ }^{19}$, as expected, considering the vocal changes commonly found in old age individuals.

The minimum intensity data obtained from both groups are values considered lower, when compared to adult women ${ }^{19}$. As for the maximum intensity from both groups, it appears with lower averages in relation to those found in young adult women aged from 18 to 29, whose average was of $113.14 \mathrm{~dB}^{19}$. Such results may be explained by the fact that adults have greater subglottic air pressure by emission than in elderly women population. The elderly may suffer the influence of loss of elasticity of lung tissue, with reduced subglottic air pressure and, consequently, reduced voice intensity. Furthermore, it is highlighted that the intensity control is directly related to laryngeal tonicity and glottal resistance, which, in elderly, may be reduced. Studies carried out with elderly women present either similar or lower average ${ }^{14,18}$.

When the parameters of vocal range profile of elderly women were compared, according to the presence or not of vocal symptoms, a similarity in average values was observed, without significant differences being recorded. It is possible that, regardless of the presence or not of vocal symptoms, the characteristics of voice range and dynamics be affected by changes of structural aspects of the vocal fold and the very condition of the mucosa in the senescence period. Moreover, it is important to consider that the similarity in result between the groups may be attributed to the fact of the vocal symptoms having been self-reported.

The main limitation to this study refers to the amount of participants. A more encompassing sample would enable a better understanding of the difficulties related to vocal range in the elderly population.

\section{CONCLUSION}

It is possible to conclude that the elderly women, in general, present reduced vocal range, which justifies the difficulty in singing presented by some participants. On the other hand, the presence or not of vocal symptoms does not seem to be related to the vocal range in elderly women. Attention is called to health programs towards the elderly that may explore their vocal efficiency, resistance and flexibility, in order to renew the possibilities of activities for the elderly in the social context, as in singing, for example, thus, improving their social integration and quality of life.

\section{REFERENCES}

1. Moraes EN. Atenção à saúde do idoso: aspectos conceituais. Brasília: Organização Pan-Americana da Saúde; 2012. p. 23-47.

2. Oliver BTNV, Dias e Dias de ML, Cabral SFC, Galdino de OTC, Picanço DNW. Estimulação multissensorial e cognitiva em idosos institucionalizados e não institucionalizados: estudo exploratório. Rev Pan-Amaz Saude. 2016;7(4):53-60.

3. Kost KM, Staloff RT. Voice disorders in the elderly. Clin Geriatr Med. 2018;34(2):191-203.

4. Pessin ABB, Tavares ELM, Gramuglia ACJ, De Carvalho LR, Martins RHG. Voice and aging: clinical, endoscopic and acoustic investigation. Clin Otolaryngol. 2017;42(2):330-5. doi: 10.1111/ coa. 12725

5. Carréra CMD, Araújo ANB, Lucena JA. Correlation between slow vital capacity and the maximum phonation time in elderly. Rev. CEFAC. 2016;18(6):1389-94.

6. Dehqan A, Scherer RC, Dashti G, AnsariMoghaddam A, Fanaie S. The effects of aging on acoustic parameters of voice. Folia Phoniatr Logop. 2012;64(6):265-70.

7. Goy H, Fernandes DN, Pichora-Fuller MK, Van Lieshout P. Normative voice data for younger and older adults. J Voice. 2013;27(5):545-5.

8. Mezzedimi C, Di Francesco M, Livi W, Spinosi MC, De Felice C. Objective evaluation of presbyphonia: spectroacoustic study on 142 patients with Praat. J Voice. 2017;31(2):257. e25-257.e32.

9. Scarpel RD, Fonseca MDL. Parâmetros acústicos de vozes de mulheres na pós-menopausa. Rev. Bras. Geriatr. Gerontol. 2014;17(4):741-50.

10. Menezes KSM, Master S, Guzman M, Bortnem C, Ramos LR. Differences in acoustic and perceptual parameters of the voice between elderly and young women at habitual and high intensity. Acta Otorrinolaryngol Esp. 2014;65(2):76-84. 
11. Roy N, Stemple J, Merril RM, Thomas L. Epidemiology of voice disorders in the elderly: preliminary findings. Laryngoscope. 2007;117(4):628-33.

12. Skingley A, Martin A, Clift $S$. The contribution of community singing groups to the well-being of older people: participant perspectives from the United Kingdom. J Appl. Gerontol. 2016;35(12):1302-24.

13. Coulton S, Clift S, Skingley A, Rodriguez J. Effectiveness and cost-effectiveness of community singing on mental health-related quality of life of older people: randomised controlled trial. B J Psychiatry. 2015;207(3):250-5.

14. Aquino FS, Ferreira LP. Vocal parameters of elderly female choir singers. Int. Arch. Otorhinolaryngol. 2016;20(1):25-9.

15. Lima AT, Lucena JA, Araújo ANB, Lira ZS, Gomes AOC. Vocal range profile of chorists after the tongue-trill technique associated with scales. Rev CEFAC. 2016;18(3):626-34.

16. Moreti F, Zambon F, Oliveira G, Behlau M. Crosscultural adaptation, validation, and cutoff values of the brazilian version of the Voice Symptom Scale - VoiSS. J Voice. 2014;28(4):458-68.

17. CTS Informática. Vocalgrama: perfil de extensão vocal e da fala. [cited 2014 Apr 17]; Disponívelem:http://www.ctsinformatica.com. br/\#vocalgrama.html \{paginaProduto!15\&1.

18. Teles-Magalhães LC, Pegoraro-Krook MI, Pegoraro R. Study of the elderly females' voice by phonetography. J Voice. 2000;14(3):310-21

19. Santos CC, Mituuti CT, Berretin-Felix G, Teles LCS. Características da fonetografia em mulheres com equilíbrio dentofacial. Rev. soc. bras. fonoaudiol. 2010;15(4):584-8.

20. Santos Filho IA, Liberali R. Comparativo de flexibilidade da voz de mulheres idosas e mulheres jovens. RBPFEX - Revista Brasileira de Prescrição e Fisiologia do Exercício. 2011;5(28):328-34.

21. Behlau MS, Pontes PAL, Ganaça MM, Tosi O. Presbifonia: tratamento da deterioração vocal inerente à idade. Acta Awho. 1988;7(2):110-5.

22. Linville SE. Maximun phonational frequency range capabilities of women's voices with advancing age. Folia Phoniatr. 1987;39(6):101-9.

23. Vargas AC, Hanayama EM. Perfil de extensão vocal em indivíduos falantes normais do português brasileiro. Rev. CEFAC. 2005;7(1):108-16.
24. Rocha TF, Amaral FP, Hanayama EM. Extensão vocal de idosos coralistas e não coralistas. Rev. CEFAC. 2007;9(2):248-54. 